\title{
ASSOCIATION BETWEEN MENTAL HEALTH DISTRESS AND WORK PRODUCTIVITY: A CROSS-SECTIONAL STUDY
}

\author{
By \\ Elotla SF, Gaafar SEM , Ameen AE and Fouad AM \\ Department of Public Health, Community Medicine, Occupational \& Environmental Medicine, Faculty of \\ Medicine, Suez Canal University, Egypt. \\ Corresponding author: Elotla SF.E-mail: sallyfawzy@med.suez.edu.eg
}

Submit Date: 2020-07-21

Revise Date: 2020-08-04

Accept Date: 2020-08-12

DOI: $10.21608 /$ ejom.2020.36674.1204

Authors' contribution: Elotla SF conceived the presented idea, developed the theoretical framework and prepared the tools. Gaafar SEM and Abeer Ameen AE performed the data collection. Fouad AM carried out data processing and analysis. All authors contributed to the final manuscript.

\begin{abstract}
Introduction: Mental health of workers is an essential determinant of their work productivity and their overall health. Poor mental health contributes meaningfully to a range of chronic physical illnesses such as hypertension, diabetes, and cardiovascular disorders. Besides, mental health distress can severely impact the ability to work, leading to increased absenteeism and/or presenteeism. Consequently, employers and businesses are negatively affected by poor mental health among their employees due to the lost productivity and profits, as well as the increased direct costs of managing these health problems. Aim of work: To investigate the association between mental health distress and work productivity in terms of absenteeism and presenteeism. Materials and Methods: One-hundred and eighty male shipyard-workers were interviewed using a predesigned questionnaire for sociodemographic characteristics, work characteristics, lifestyle behaviors, perceived health status, and chronic diseases. Mental health distress was measured using the Kessler psychological distress scale (K6), while measures of work productivity (absenteeism and presenteeism) were calculated according to the scoring guide of the Health and Work Performance Questionnaire (HPQ-short form). Results: The mean age of participants was 48.3 years $( \pm 8.17)$. Operators
\end{abstract}




\begin{abstract}
and service-workers constituted $73.3 \%$ of all participants, while professionals and administrative workers represented $16.7 \%$ and $10 \%$, respectively. Eight workers (4.4\%) had high mental health distress, while $12.2 \%$ had moderate distress. The mean days of absenteeism and presenteeism were significantly higher among participants with moderate or high mental distress compared to low distress $(p<0.001)$. Further, within each level of mental distress, the mean presenteeism days were significantly higher than the mean absenteeism days. Moderate and high mental distresses were associated with 2.1 and 3.9 times greater rates of absenteeism and presenteeism compared to low mental distress. Conclusion: Mental health distress is associated with both higher absence and presenteeism rates. Effective workplace policies for mental health promotion and case management could yield substantial increases in worker's productivity.
\end{abstract}

Keywords: Mental health, Presenteeism, Absenteeism and Work productivity

\section{Introduction}

Mental illnesses are universally widespread and quite expensive. It is projected that one in five working adults would have a mental health issue, with a lifetime prevalence rate of around 50\% (OECD, 2012 and Bubonya et al., 2017). Mental illnesses among working adults are costly not only for society but also for families, health systems, individuals, and employers (Memish et al. 2017). In England, the overall economic costs of mental illnesses in the financial year 2009-2010 were reported to be $£ 105.2$ billion (Centre for Mental Health, 2010), while in the United States, severe mental illness is correlated with a gross annual earnings loss of $\$ 193.2$ billion (Kessler et al.,
2008). For employers, mental health problems are amongst the top 10 health conditions that induce health-related costs (Hilton et al., 2008).

Poor mental health accounts for a substantial decline in employees' work productivity (Hilton et al., 2008). Work productivity has two key components; absenteeism (i.e., not attending work in the first place) and presenteeism (i.e., attending work but not being well enough to work up to normal standards) (Sanderson et al., 2003; Hilton et al., 2008; and OECD, 2012). However, recent literature demonstrates that presenteeism accounts for the most considerable productivity loss due to mental illness (The Sainsbury Centre for Mental health, 2007). The concern 
in presenteeism is relatively recent and derives from the increasing awareness that there are significant losses in efficiency occurring due to workers attending while they are sick. As a matter of fact, in chronic disorders cases and mental wellbeing, the total productivity deficit associated with presenteeism has been estimated to be higher than that due to absenteeism (Collins et al., 2005). A recent Brazilian study indicated that the burden of presenteeism is higher than absenteeism. Further, the study reported that mental disorders were associated with more workdays lost because of absenteeism and presenteeism than workdays lost due to physical diseases (Baptista et al., 2019).

Michie and Williams (2008) had performed a thorough analysis of workrelated factors of mental illnesses. They found that numerous work and organizational factors were associated with mental illnesses including; long hours of work, unmanageable workload and stress, loss of the power to work, loss of decision-making involvement, inadequate social care, and uncertain management and position in the task .

Stress-induced poor health has been estimated to lead to about 30.9 workdays missed (WHO, 2010). Furthermore, a decline in psychological and physical wellbeing from stress exposure can result in suboptimal results, which can lead to injuries and other quality issues and decreased productivity, thus increasing operating risks (Leka and Jain, 2017). In the European Union, absenteeism, long-term disability, and unemployment assert due to workrelated tension and mental health issues are rising (McDaid, 2008). In 2007, around $40 \%$ of long-termed disability payments in the UK were due to mental disorders, while in Austria, there was a $56 \%$ net rise in the absence due to sickness related to mental illness (Zechmeister, 2004; and Sainsbury et al., 2008).

\section{Aim of work}

To investigate the association between mental health distress workers' productivity in terms of absenteeism and presenteeism.

\section{Materials and Methods}

Study design: This is a crosssectional study.

Place and duration of the study: This study was conducted at ArabContractors Co. Shipyard in Ismailia governorate during June 2020. 
Study sample: A sample of 180 male workers were selected from an available sampling frame of about 2500 workers who spent at least two years in their current job. The selection of participants was performed using a stratified random sampling technique, in which proportionate random samples were drawn from two job strata (blue and white-collars). The sample size was calculated based on an estimated $10.42 \%$ prevalence of workers with poor mental health who had been absented for at least one day in the last 30-days period (Bubonya et al., 2017); at 95\% level of confidence, and $5 \%$ absolute precision level $(10 \%$ of the calculated sample size was added to compensate for dropout).

\section{Study methods:}

1. A predesigned intervieweradministrated questionnaire was used to collect data about participant's sociodemographic data, work characteristics, lifestyle behaviors, perceived health status, and chronic health problems.

\section{Kessler psychological distress} scale (6-items, K6): is a six-item scale for assessment of psychological distress with excellent internal consistency, reliability, and strong discrimination between community mental health cases and non-cases. Kessler's scale (K6 version) for mental health assessment includes six main types of symptoms: sadness or depression, nervousness, restlessness or fidgety, hopelessness, low-energy, and worthlessness. Each of the six items on the $\mathrm{K} 6$ is rated by the respondent on a five-point scale from «none of the time» (value $=0$ ) to 〈all of the time (value $=4$ ). The K6 is scored by the summation of the response values, with a maximum score of 24. Calibration studies indicated that a score of 13 to 24 corresponds to high psychological distress, 8-12 moderate psychological distress and, 0-7 low psychological distress (Hilton et al., 2009).

\section{Health and Work Performance} Questionnaire (HPQ): In the shortform HPQ, absolute absenteeism is calculated as the absolute difference between the number of hours per week actually worked by each employee, and the hours per week employer does expect his employees to work. Presenteeism is the day-equivalent value of the decrement in the work performance relative to the average work performance of coworkers. Then, presenteeism was calculated as the product of multiplying 
the percent decrement in the relative worker's performance, and the hours actually worked in the past month. Both absenteeism and presenteeism were presented as the mean days lost per month (Kessler, 2003).

\section{Calculation of Body Mass} Index (BMI): BMI was calculated as $\mathrm{kg} /(\mathrm{m})^{2}$, where $\mathrm{kg}$ was the self-reported worker's weight in kilograms, and (m) ${ }^{2}$ is his self-reported height in meters squared. The Center for Disease Control and Prevention (CDC) classification for BMI was used to define overweight and obesity (CDC, 2020), where workers were overweight if they had a BMI from 25.5 to 29.9 , and obese, if they had a BMI, of 30 or more.

\section{Consent}

All participants have given their written informed consent before participating in this study.

\section{Ethical approval}

Ethical approval was obtained from the Ethical Committee at the Faculty of Medicine, Suez Canal University.

\section{Data management}

All data analyses were performed with the statistical package for social science SPSS version 25. Descriptive statistics were used for describing and summarizing data as appropriate (mean and standard deviation for continuous variables, and frequency and percentage for categorical variables). The normality of data was tested graphically and statistically with the Kolmogorov Smirnov test of normality. Kruskal Wallis test was used to test for the statistical significance of differences in absenteeism and presenteeism between the mental distress levels, while Wilcoxon signed-rank test was used for testing the statistical significance of differences between absenteeism and presenteeism within each mental distress level. Negative binomial regression analysis was performed to test for the association between mental health distress and each of the absenteeism and presenteeism rates, controlling for other study variables. Statistical significance was considered if $\mathrm{p}<0.05$. 


\section{Results}

Table 1: Sociodemographic and work characteristics of the studied population ( $\mathrm{No}=180)$.

\begin{tabular}{|c|c|}
\hline Variables & Mean \pm SD \\
\hline Age (years) & $48.34 \pm 8.17$ (Range: $29-59)$ \\
\hline$<40$ & $24(13.3 \%)$ \\
\hline $40-$ & $63(35.0 \%)$ \\
\hline $50-60$ & $93(51.7 \%)$ \\
\hline \multicolumn{2}{|l|}{ Education Level } \\
\hline Primary or Less & $41(22.8 \%)$ \\
\hline Secondary & $107(59.4 \%)$ \\
\hline Higher Education & $32(17.8 \%)$ \\
\hline \multicolumn{2}{|l|}{ Marital Status } \\
\hline Single & $9(5.0 \%)$ \\
\hline Married & $171(95.0 \%)$ \\
\hline \multicolumn{2}{|l|}{ Number of Children } \\
\hline None & $14(7.8 \%)$ \\
\hline $1-2$ & $28(15.6 \%)$ \\
\hline$>2$ & $138(76.7 \%)$ \\
\hline \multicolumn{2}{|l|}{ Residence } \\
\hline Rural & $34(18.9 \%)$ \\
\hline Urban & $146(81.1 \%)$ \\
\hline \multicolumn{2}{|l|}{ Duration of Employment } \\
\hline$<15$ & $46(25.6 \%)$ \\
\hline $15-30$ & $59(32.8 \%)$ \\
\hline$>30$ & $75(41.7 \%)$ \\
\hline \multicolumn{2}{|l|}{ Job category } \\
\hline Administrative & $18(10.0 \%)$ \\
\hline Professionals & $30(16.7 \%)$ \\
\hline Operators/ Services & $132(73.3 \%)$ \\
\hline \multicolumn{2}{|l|}{ Shiftwork } \\
\hline Day shift & $124(68.9 \%)$ \\
\hline Rotating shift & $56(31.1 \%)$ \\
\hline \multicolumn{2}{|l|}{ Work Productivity } \\
\hline Absenteeism (days) & $1.00 \pm 1.14$ (Range: $0-6$ ) \\
\hline Presenteeism (days) & $1.52 \pm 1.93$ (Range: $0-9)$ \\
\hline
\end{tabular}


Table (1) showed that this study included 180 male workers aged from 29 to 59 years, with a mean age of 48.3 years. More than half of the participants $(59.4 \%)$ had a secondary-education degree. The majority of participants were married (95\%), had more than two children (76.7\%), and residing in urban areas $(81.1 \%)$. About two-thirds of participants have worked in the current workplace for 15 years or more. Operators and service workers constituted $73.3 \%$ of all participants, while the majority was day-shift workers $(68.9 \%)$.

Table 2: Lifestyle and health-related characteristics of the studied population (No $=180)$.

\begin{tabular}{|c|c|}
\hline Variables & Mean \pm SD \\
\hline \multicolumn{2}{|l|}{ Lifestyle behaviors } \\
\hline Cigarette smoking & $109(60.6 \%)$ \\
\hline Physically active & $58(32.2 \%)$ \\
\hline Body Mass Index (BMI) & $26.60 \pm 2.85($ Range: $19.20-36.48)$ \\
\hline \multicolumn{2}{|l|}{ BMI Class: } \\
\hline Normal & $76(42.2 \%)$ \\
\hline Overweight & $85(47.2 \%)$ \\
\hline Obese & $19(10.6 \%)$ \\
\hline \multicolumn{2}{|l|}{ Chronic medical conditions: } \\
\hline NO & $155(86.1 \%)$ \\
\hline Yes & $25(13.9 \%)$ \\
\hline \multicolumn{2}{|l|}{ Perceived physical health status } \\
\hline Excellent/ Very good & $23(12.8 \%)$ \\
\hline Good & $88(48.9 \%)$ \\
\hline Fair & $54(30.0 \%)$ \\
\hline Poor & $15(8.3 \%)$ \\
\hline \multicolumn{2}{|l|}{ Perceived mental health status } \\
\hline Excellent/ Very good & $30(16.7 \%)$ \\
\hline Good & $133(73.9 \%)$ \\
\hline Fair & $17(9.4 \%)$ \\
\hline
\end{tabular}

Table (2) showed that $61 \%$ of the participants were cigarette smokers, and $32 \%$ were practicing regular physical activity. The mean Body Mass Index (BMI) was $26.6 \mathrm{~kg} / \mathrm{m}^{2}$ and ranged from 19 to $36.5 \mathrm{~kg} / \mathrm{m}^{2}$. Accordingly, about half of the 
participants were overweight, and $10.6 \%$ were obese. About $14 \%$ of participants had at least a single chronic disease and receiving medical treatment for at least two years (participants with mental diseases were excluded). About two-thirds of participants believed that they had good-to-excellent physical health, while about $91 \%$ of them believed that they had good-to-excellent mental health.

Table 3: Mental health symptoms among the studied population $(\mathrm{No}=180)$.

\begin{tabular}{|c|c|}
\hline Variables & No. $(\%)$ \\
\hline \multicolumn{2}{|l|}{ K6-based symptoms (in the past four weeks) } \\
\hline Sad, nothing could cheer him up & $37(20.6 \%)$ \\
\hline Nervous & $23(12.8 \%)$ \\
\hline Restless or fidgety & $21(11.7 \%)$ \\
\hline Hopeless & $15(8.3 \%)$ \\
\hline Low energy & $49(27.2 \%)$ \\
\hline Worthless & $12(6.7 \%)$ \\
\hline \multicolumn{2}{|l|}{ Other symptoms (in the past four weeks) } \\
\hline Impatient or irritable & $15(8.3 \%)$ \\
\hline $\begin{array}{l}\text { Very tired, weak, or exhausted while performing minor } \\
\text { physical daily activities }\end{array}$ & $25(13.9 \%)$ \\
\hline $\begin{array}{l}\text { Very tired, weak, or exhausted while performing minor } \\
\text { daily mental tasks (e.g., reading, writing, doing paperwork) }\end{array}$ & $22(12.2 \%)$ \\
\hline Unable to relax or rest after severe tiredness & $13(7.2 \%)$ \\
\hline $\begin{array}{l}\text { Sleep disturbances (getting to sleep, staying asleep, waking } \\
\text { too early, or day sleepiness) }\end{array}$ & $41(22.8 \%)$ \\
\hline Difficulty in remembering appointments or obligations & $12(6.7 \%)$ \\
\hline \multicolumn{2}{|l|}{ Kessler (k6) total score for Mental Distress } \\
\hline Low $(0-7)$ & $150(83.3 \%)$ \\
\hline Moderate $(8-12)$ & $22(12.2 \%)$ \\
\hline $\operatorname{High}(13-24)$ & $8(4.4 \%)$ \\
\hline
\end{tabular}


Table (3) showed that low energy and depression $(27.2 \%$ and $20.6 \%$, respectively) were the most frequent k6-related symptoms in our studied population, while the least frequent ones were worthlessness and hopelessness $(6.7 \%$ and $8.3 \%$, respectively). Further, sleep disturbances, physical and mental exhaustion, were other common symptoms for mental health distress $(22.8 \%, 13.9 \%$, and $12.2 \%$, respectively). Irritability and inability to relax after severe tiredness were reported by $8.3 \%$ and $7.2 \%$ of participants, while memory difficulties existed among $6.7 \%$ of participants. According to the K6 total score, $4.4 \%$ of participants had high mental health distress, while $12.2 \%$ had moderate one.

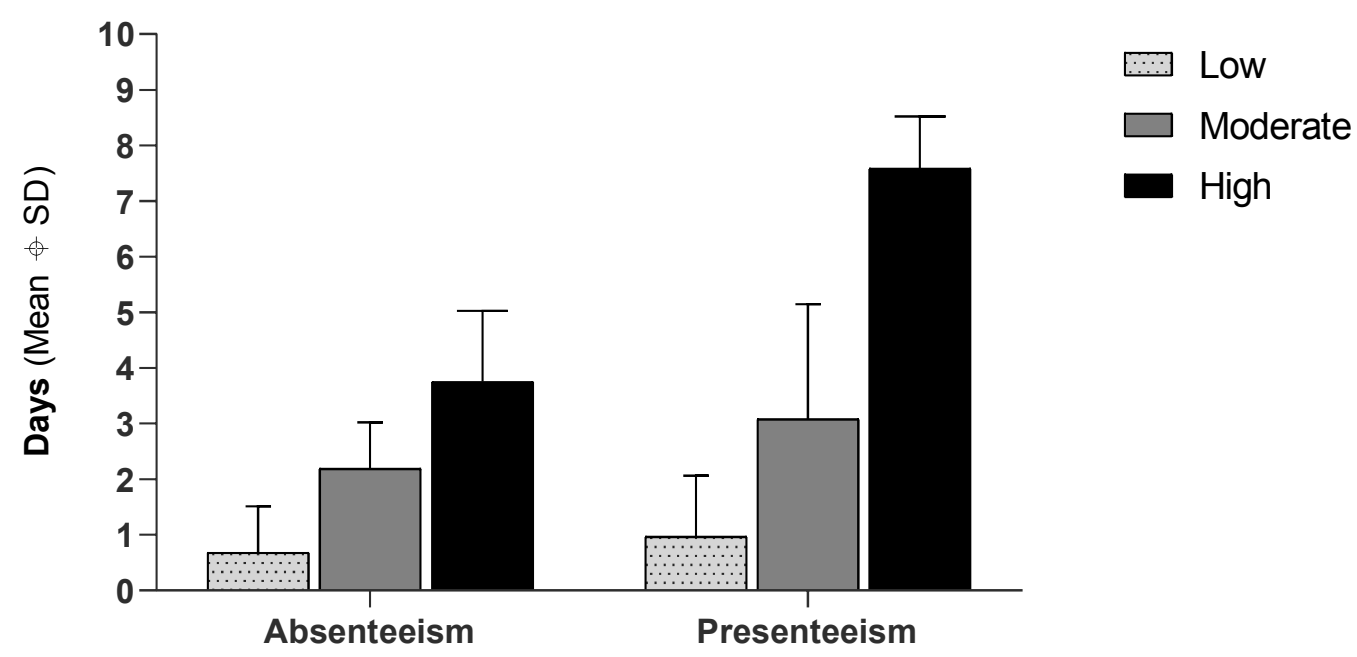

Figure 1. Distribution of absenteeism and presenteeism by the level of mental health distress.

Figure 1 showed that the mean days of absenteeism and presenteeism were significantly higher among participants with moderate or high mental distress compared to low distress $(\mathrm{p}<0.001)$. Further, within each level of mental distress, the mean presenteeism days was significantly higher than the mean absenteeism days (Low: $\mathrm{p}=0.008$; Moderate: $\mathrm{p}=0.035$; High: $\mathrm{p}=0.012$ ). 
Table 4: Regression analysis for the predictors of absenteeism and presenteeism among the studied population $(\mathrm{No}=180)$.

\begin{tabular}{|c|c|c|}
\hline & Absenteeism (days) & Presenteeism (days) \\
\hline & OR $(95 \% \mathrm{CI})$ & OR $(95 \% \mathrm{CI})$ \\
\hline \multicolumn{3}{|l|}{ Age (vs. $<40$ years) } \\
\hline $40-49$ & $0.57(0.27-1.21)$ & $0.94(0.52-1.71)$ \\
\hline $50-60$ & $0.46(0.18-1.18)$ & $0.74(0.36-1.52)$ \\
\hline \multicolumn{3}{|l|}{ Education level } \\
\hline Secondary & $0.96(0.66-1.39)$ & $0.97(0.71-1.32)$ \\
\hline Higher Education & $1.08(0.66-1.76)$ & $1.15(0.77-1.70)$ \\
\hline Rural residence (vs. Urban) & $0.87(0.58-1.30)$ & $0.86(0.61-1.20)$ \\
\hline \multicolumn{3}{|l|}{ Number of children (vs. None) } \\
\hline $1-2$ & $1.78(0.71-4.44)$ & $3.04(1.24-7.50)^{*}$ \\
\hline$>2$ & $1.85(0.74-4.62)$ & $3.42(1.40-8.32)^{*}$ \\
\hline \multicolumn{3}{|l|}{ Duration of employment (vs. < 15) } \\
\hline $15-30$ & $1.45(0.82-2.55)$ & $0.87(0.57-1.33)$ \\
\hline$>30$ & $1.51(0.75-3.06)$ & $1.09(0.64-1.86)$ \\
\hline \multicolumn{3}{|l|}{ Job category (vs. administrative) } \\
\hline Professionals & $1.71(0.78-3.72)$ & $1.38(0.78-2.43)$ \\
\hline Operators/ Services & $2.09(1.04-4.18)^{*}$ & $1.24(0.75-2.05)$ \\
\hline Rotating-shift (vs. Day-shift) & $0.74(0.51-1.06)$ & $0.92(0.68-1.23)$ \\
\hline \multicolumn{3}{|l|}{ BMI class (vs. Normal) } \\
\hline Overweight & $0.86(0.55-1.34)$ & $1.11(0.76-1.62)$ \\
\hline Obese & $1.34(0.74-2.43)$ & $1.17(0.71-1.92)$ \\
\hline Physically active (vs. sedentary) & $0.74(0.48-1.16)$ & $1.13(0.79-1.64)$ \\
\hline Cigarette smoker (vs. non-smoker) & $1.30(1.00-1.84)^{*}$ & $1.01(0.76-1.35)$ \\
\hline Chronic medical condition (vs. None) & $1.74(1.02-2.98) *$ & $1.99(1.27-3.12)^{*}$ \\
\hline \multicolumn{3}{|l|}{ Mental health distress (vs. Low) } \\
\hline Moderate & $2.30(1.38-3.50) *$ & $2.05(1.37-3.07)^{*}$ \\
\hline High & $2.52(2.29-4.93) *$ & $3.90(2.26-6.74) *$ \\
\hline
\end{tabular}

*: Statistically significant p-value $(<0.05)$.
OR = Odds Ratio
$\mathrm{CI}=$ Confidence Interval 
In table 4, the job category, cigarette smoking, chronic diseases, and mental health distress were the significant predictors for the absenteeism rate among our study participants. In contrast, the number of children, chronic diseases, and mental health distress were the only significant predictors for the presenteeism rate. Operators or service workers had about two-times higher absenteeism rates compared to administrative workers. Cigarette smokers had a 30\% increased absenteeism rate compared to non-smokers. Participants with chronic diseases had a 74\% increased absenteeism rate compared to non-diseased workers. Compared to participants with low mental health distress, moderate and high mental distress were associated with 2.3 and 2.5 times greater rates of absenteeism, respectively. In contrast, participants with 1-2 children or more than two children had about 3 or 3.4 times greater presenteeism rate compared to participants who had no children. Having a chronic disease was associated with a $99 \%$ increased presenteeism rates, while the moderate and high mental distress were associated with 2.1 and 3.9 times greater rates compared to low mental distress.

\section{Discussion}

Psychological distress is a state of emotional suffering presented by depression (e.g., lost interest, sadness, hopelessness) and anxiety (e.g., restlessness and feeling tense) and may be associated with somatic symptoms (e.g., headaches, insomnia, and lack of energy). It is commonly used as a mental health indicator (Drapeau et al., 2012).

To examine the prevalence of psychological distress among studied participants, they were invited to complete the K6 psychological distress scale. It was found that high mental health distress was prevalent in $4.4 \%$ of participants, while $12.2 \%$ had moderate distress (Table 3). These findings were matched with a study conducted by Leibler et al. (2017), which reported that the prevalence of psychological distress was $4.4 \%$, and the prevalence of mild and moderate psychological distress was $14.6 \%$. Likewise, Hilton et al. (2008) declared a prevalence of $4.5 \%$ for high psychological distress. Similarly, Matsuoke et al. (2012) revealed that the prevalence of severe mental illness, as determined by the K6, was $4.0 \%$. On the other hand, Fushimi et al. (2012) found a higher prevalence rate, as many as $10.8 \%$ of the employees 
exhibited high levels of psychological distress.

In the current study, a statistically significant association was detected between the mean days of absenteeism and presenteeism and level of distress (Table 4). Our results were supported by Suzuki et al. (2015), who found that high levels of absenteeism or presenteeism were significantly associated with higher rates of depression. Furthermore, within each level of mental distress, the mean presenteeism days were significantly higher than the mean absenteeism days. This finding corroborates those of Hilton et al. (2008), who documented that presenteeism is associated with a higher cost burden on the employer than absenteeism.

Risk factors of absenteeism and presenteeism are multidimensional, ranging from organizational culture and job-related elements to individual differences. In terms of sociodemographic data, in this study, younger workers have a higher tendency for absenteeism and presenteeism (Table 4). These findings were consistent with Wee et al. (2019), who found that younger workers had a higher prevalence of presenteeism than older workers. This may be because younger workers have less experience and operation skills as compared to older ones.

A worker's educational achievement plays an essential role in his behavior. The current study revealed that participants with lower education levels reported more absenteeism and presenteeism rates (Table 4). In contrast to our results, Vuorio et al., 2019 and Yi and Kim, 2020 found that higher education was associated with lower absenteeism and presenteeism rates. This could be explained that lower educational status is often connected to more physically strenuous work, which in turn is also known to be a risk factor for absenteeism and decreased work ability (Tuomi et al., 1999) and operators and service-workers' dominance represents $73.3 \%$ of our study population (Table 2).

Regarding parental responsibility, our results showed that participants who had children were more likely to exhibit presenteeism than their counterparts with no children. This was in agreement with a study done by Johns (2011) who observed that the presence of young children positively influences the number of days of presenteeism without effect on absenteeism. 
Cigarette smoking was a significant predictor for the absenteeism rate among our study participants (Table 4). This study finding was in line with the findings of a prior study that revealed that smokers are more likely to take time off from work, thereby decreasing their contribution to their organization's productivity indicators (Tsai, 2005).

In the present study, there was no significant relationship between cigarette smoking and presenteeism (Table 4). This result adheres to the finding of a meta-analysis conducted by Heishman et al., (2010), highlighting that people who smoke have better motor abilities, attention, and memory improvement than people who do not smoke. Furthermore, smokers were found to not only be more productive but also to produce work that was of a higher standard than those who did not smoke. Furthermore, employees who smoke generally take their smoke breaks together, thereby increasing communication between a group of people. Because smokers have moved away from their desks to smoke, their new environment may feel more relaxed, which supports more creative and innovative ways of thinking. During these smoke breaks, it may be the case that smokers receive or overhear, information that assists in the execution of work tasks and objectives (Steyn et al., 2006).

The present work revealed that the job category has a significant influence on the absenteeism rate only, not presenteeism (Table 4). This finding was partially consistent with Kessler and Frank (1997), who revealed that the job category did not significantly influence both work loss and presenteeism days. Also, Yi and Kim (2020) found that job type did not show any significant effect on presenteeism.

The results of the current study showed that the presence of chronic diseases was significant predictors for the absenteeism rate (Table 4). This result echoed that of preceding studies that reported that employees who were suffering from chronic illnesses were more likely to report absenteeism (Ubalde-Lopez et al. 2017 and Vuorio et al., 2019).

The results of the existing study also found that suffering from a chronic disease is a significant predictor for presenteeism (Table 4). This finding was consistent with studies done by Rantanen and Tuominen (2011) in their work on the prevalence and incidence 
rates of diseases and work ability in different work categories of municipal occupations and Allemann et al. (2019) in their study on predictors of presenteeism among hospital employees in Switzerland, which revealed that the presence of chronic diseases increases the rates of presenteeism.

Apart from physical health, our results pointed out that mental health was found to predict both absenteeism and, to a greater extent, presenteeism (Table 4). Similar results were presented in a study done by Allemann and his colleagues (2019), linking mental strain with presenteeism. Brborovic and his team (2016) had a similar conclusion, documenting that workers suffering from higher levels of stress were more likely to go to work while they were ill (i.e., had more presenteeism days). The greater effect of stress on presenteeism may be explained by the fact that cultural contexts in which mental illness is stigmatized may prevent an employee from disclosing their mental illness status and take sick-leave due to mental health-related reasons (EvansLacko and Knapp, 2016).

Study Limitation: This crosssectional study could not ascertain the temporal relationship between mental health distress and work absence and presenteeism. So, longitudinal studies are needed. Also, the study could not investigate the gender differences in mental health distress or work productivity because female workers were not wellrepresented in such type of industry. Further studies in different industrial sectors with better representation of gender differences are needed.

Conclusion: Mental health of workers contributes meaningfully to their work productivity and their overall health. Findings of this study revealed that moderate-to-high mental health distress substantially existed among the study participants. Increased mental health distress is associated with both higher absence and presenteeism rates. Therefore, the implementation of workplace policies for mental health promotion and case management could yield a substantial decrease in lost productivity among workers with poor mental health.

\section{Conflict of interest}

All authors of this manuscript declared that they have no financial or personal relationships with other people or organizations that could inappropriately influence this work. 


\section{Funding}

No funding was received to conduct this study.

\section{Acknowledgment}

Authors acknowledged the administration of Arab Contractors Co. Shipyard at Ismailia for facilitating outreach participants of this study. Also, they acknowledged all workers who participated in this study.

\section{References}

1. Allemann A, Siebenhuner K, and Hammig O (2019): Predictors of Presenteeism among Hospital Employees: A Cross-Sectional Questionnaire-Based Study in Switzerland. J Occup Environ; 61(12):1004-10. DOI: 10.1097/JOM.0000000000001721.

2. Baptista MC, Burton WN, Nahas AK, Wang YP, Viana MC, et al. (2019): Absenteeism and presenteeism Associated with Common Health Conditions in Brazilian Workers. J Occup Environ; 61(4):303-13. DOI: 10.1097/ JOM.0000000000001538

3. Brborovic $\mathrm{H}$, Brborovic $\mathrm{O}$ and Mustajbegovic J (2016): Looking for the possible association between stress, presenteeism and absenteeism among Croatian nurses: a cross-sectional study. Iran J Psychiatry Behav Sci; 10(4): e4587. DOI: 10.17795/ijpbs-4587

4. Bubonya M, Cobb-Clark DA, and Wooden M (2017): Mental health and productivity at work: Does what you do matter? Labour Economics; 46:150-65.

5. Center for Disease Control and Prevention
(CDC) (2020): Defining Adult Overweight and Obesity. Division of Nutrition, Physical Activity, and Obesity, National Center for Chronic Disease Prevention and Health Promotion. Page last reviewed: June 30, 2020. Available at https://www.cdc.gov/obesity/adult/ defining.html.

6. Collins J, Baase C, Sharda C, Ozminkowski R, Nicholson S, et al. (2005): The assessment of chronic health conditions on work performance, absence, and total economic impact for employers. J Occup Environ; 47(6): 547-57.

7. Drapeau A, MarchandA, and Beaulieu-PrévostD (2012): Epidemiology of psychological distress. In: Mental Illnesses - understanding, prediction and control. Luciano L'Abate, IntechOpen, pp.105-34. DOI: 10.5772/30872. Available at: http://www.intechopen.com/books/mentalillnesses-understanding-prediction-and-control/ epidemiology-of-psychological-distress.

8. Evans-Lacko S, and Knapp M (2016): Global patterns of workplace productivity for people with depression: Absenteeism and presenteeism costs across eight diverse countries. Soc Psychiatry Psychiatr Epidemiol; 51(11), 152537. DOI: $10.1007 / \mathrm{s} 00127-016-1278-4$.

9. Fushimi M, Saito S, Shimizu T, Kudo Y, Seki M, et al. (2012): Prevalence of psychological distress, as measured by the Kessler 6 (K6), and related factors in Japanese employees. Community Ment Health J; 48:328-35. DOI: 10.1007/s10597-011-9416-7.

10. Heishman SJ, Kleykamp BA and Singleton EG (2010): Meta-Analysis of the Acute Effects of Nicotine and Smoking on Human Performance. Psychopharmacology; 210(4), 453-69. DOI. org/10.1007/s00213-010-1848-1.

11. Hilton MF, Whiteford HA, Sheridan JS, Cleary CM, Chant DC, et al. (2008): The prevalence of psychological distress in employees and associated occupational risk factors. Occup 
Environ Med; 50(7):746-57. DOI:10.1097/ JOM.0b013e31817e9171. PMID: 18617830

12. Hilton MF, Scuffham PA, Sheridan J, Psych MC, Cleary CM, et al. (2008): Mental Ill-Health and the Differential Effect of Employee Type on Absenteeism and Presenteeism. J Occup Environ; 50 (11): 1228-43. DOI:10.1097/ JOM.0b013e31818c30a 8

13. Hilton MF, Sheridan J, Cleary CM, and Whiteford HA (2009): Employee absenteeism measures reflecting current work practices may be instrumental in a re $\square$ evaluation of the relationship between psychological distress/ mental health and absenteeism. Int J Methods Psychiatr Res; 18(1):37-47. DOI: 10.1002/ mpr.275

14. Hossain N, Nur F, and Jaradat RM (2016): An analytical study of hazard and risks in the shipbuilding industry. Proceedings of the International Annual Conference of the American Society for Engineering Management (ASEM).Available at : http://www.cavs.msstate. edu/publications/docs/2016/08/14947Final.pdf

15. Johns G (2011): Attendance dynamics at work: The antecedents and correlates of presenteeism, absenteeism, and productivity loss. J Occup Health Psychol; 16(4):483-500. DOI: 10.1037/ a0025153.

16. Kessler RC and Frank RG (1997): The impact of psychiatric disorders on work loss days. Psychol Med; 27(4):861-73. DOI: 10.1017/ s0033291797004807.

17. Kessler RC (2003): HPQ scoring documents: Harvard Medical School. Available at: https:// www.hcp.med.harvard.edu/hpq/info.php.

18. Kessler RC, Akiskal HS, Ames M, Birnbaum H, Greenberg P, et al. (2006): Prevalence and effects of mood disorders on work performance in a nationally representative sample of U.S. workers. Am J Psychiatry; 163(9):1561-68.
19. Kessler RC, Heeringa S, Lakoma MD, Petukhova M, Rupp AE, et al. (2008): Individual and societal effects of mental disorders on earnings in the United States: results from the National Comorbidity Survey Replication. Am J Psychiatry; 165 (6): 703-11.

20. Leibler JH, Janulewicz PA, and Perry MJ (2017): Prevalence of serious psychological distress among slaughterhouse workers at a United States beef packing plant. Work; 57(1):105-9. DOI: $10.3233 /$ WOR-172543.

21. Leka S, and Jain A (2017): Eu Compass for Action On Mental Health and Well-Being, Mental Health in The Workplace in Europe - Consensus Paper - The European Union in the frame of the $3^{\text {rd }}$ EU Health Programme (2014-2020).Available at : https://ec.europa. eu/health/sites/health/files/mental_health/docs/ compass_2017workplace_en.pdf

22. Matsuoka Y, Nishi D, Nakaya N, Sone T, Noguchi H, et al. (2012): Concern over radiation exposure and psychological distress among rescue workers following the Great East Japan Earthquake. BMC Public Health; 15: 12:249. DOI: 10.1186/1471-2458-12-249.

23. McDaid D (2008): Mental Health in Workplace Settings. Consensus Paper, European Communities, Luxembourg. Available at : http://www.mentalhealthpromotion.net/ resources/mental-health-in-workplace-settings--consensus-paper.pdf

24. Memish K, Martin A, Bartlett L, Dawkins S, and Sanderson K (2017): Workplace mental health: An international review of guidelines. Prev Med;101:213-22. DOI: 10.1016/j. ypmed.2017.03.017.

25. Michie S and Williams S (2003): Reducing work-related psychological ill health and sickness absence: A systematic literature review. J Occup Environ Med; 60:3-9. DOI: 10.1136/ oem.60.1.3 
26. Organization for Economic Co-operation and Development (OECD) (2013): Sick on the Job? Myths and Realities about Mental Health and Work. Paris: OECD Publishing. Retrieved from:http://www.oecdilibrary.org/employment/ oecd-employment-outlook-2013_empl_ outlook-2013-en.

27. Rantanen I, and Tuominen R (2011): Relative magnitude of presenteeism and absenteeism and work-related factors affecting them among health care professionals. Int Arch Occup Environ Health; 84(2):225-30. DOI: 10.1007/ s00420-010-0604-5.

28. Sainsbury R, Irvine A, Aston $\mathrm{J}$, Wilson S, Williams C, et. al (2008). Mental health and employment (research report No 513), Department for Work and Pensions. Available at: http://eprints.whiterose.ac.uk/73459/2/ Document.pdf

29. Sanderson K, Tilse E, Nicholson J, Oldenburg B, and Graves N (2007). Which presenteeism measures are more sensitive to depression and anxiety? J Affect Disord; 101:65-74.

30. Steyn NP, Bradshaw D, Norman R, Joubert J, Schneider M, et. al (2006): Dietary Changes and the health transition in South Africa: Implications for Health Policy. In The Double Burden of Malnutrition: Case Studies from Six Developing Countries. Rome, FAO. Pp.259 -304. Available at: http://www.fao.org/3/ a0442e/a0442e0v.htm

31. Suzuki T, Miyaki K, Song Y, Tsutsumi A, Kawakami N, et al. (2015): Relationship between sickness presenteeism (WHO-HPQ) with depression and sickness absence due to mental disease in a cohort of Japanese workers. J Affect Disord; 180:14-20. DOI:10.1016/j. jad.2015.03.034

32. The Sainsbury Centre for Mental health (2007): Policy Paper 8: Mental Health at Work: Developing the Business Case.
London, UK: The Sainsbury Centre for Mental Health; 2007.Available at: https://www. centreformentalhealth.org.uk/sites/default/ files/2018-09/mental_health_at_work.pdf

33. Tsai SP, Wen CP, Hu SC, Cheng TY and Huang SJ (2005): Workplace Smoking Related Absenteeism and Productivity Costs in Taiwan. Tob Control; 14(1):i33-7. DOI: 10.1136/ tc.2003.005561.

34. Tuomi K, Ilmarinen J, Eskelinen L, Järvinen E, Toikkanen J, et. al (1991): Prevalence and incidence rates of diseases and work ability in different work categories of municipal occupations. Scand J Work Environ Health; 1(17):67-74.

35. Ubalde Lopez M, Delclos GL, Benavides FG, Calvo-Bonacho E and Gimeno D (2017): The effect of multimorbidity on sickness absence by specific diagnoses. Occup Med (Lond); 67(2):93-100. DOI: 10.1093/ occmed/kqw092.

36. Vuorio T, Suominen S, Kautiainen H and Korhonen P (2019): Determinants of Sickness Absence Rate among Finnish Municipal Employees. Scand J Prim Health Care; 37(1):39. DOI: $10.1080 / 02813432.2019 .1568710$.

37. Wee LH, Yeap LLL, Chan CMH, Wong JE, Jamil NA, et al. (2019): Anteceding factors predicting absenteeism and presenteeism in urban area in Malaysia. BMC Public Health; 19 (4):540. DOI: 10.1186/s12889-019-6860-8.

38. World Health Organization (2010): Health impact of psychosocial hazards at work: An overview. Geneva: World Health Organization (WHO). Available at: http://www.who. int/occupational_health/publications/ hazardpsychosocial/en/index.html

39. Yi JS, and Kim H (2020): Factors Related to Presenteeism among South Korean Workers Exposed to Workplace Psychological Adverse 
Social Behavior. Int J Environ Res Public Health; 17(10):3472. DOI:10.3390/ijerph17103472

40. Zechmeister I (2004): Financing Mental Health
Systems - Austria. London: Mental health Economics European Network. Available at: http://icmpe.org/test1/journal/issues/ v5pdf/5-121_text.pdf 